\title{
A retrospective study of root apices closure of permanent incisors and first molars in Tanzanian children's digital Orthopantomographs
}

Twalha Hamisi Mituro $^{1 \dagger}$, Emeria Abella Mugonzibwa ${ }^{2 *}$ and Febronia Kokulengya Kahabuka ${ }^{2 \dagger}$

*Correspondence: mugonzibwamwanga@gmail.com

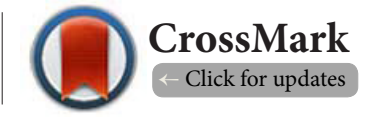

${ }^{\dagger}$ These authors contributed equally to this work.

1 Dental Department, Muhimbili National Hospital, Dar es Salaam, Tanzania.

${ }^{2}$ Department of Orthodontics, Paedodontics and Community Dentistry, Muhimbili University of Health and Allied Sciences (MUHAS),

Dar es Salaam, Tanzania.

\begin{abstract}
Background: Development status of the root apices of permanent teeth is important in various dental disciplines, paediatrics, endocrinology and forensic dentistry.

Aim: To assess the root apices closure of permanent incisors and first molars among Tanzanian children aged 6-15 years.

Methods: A hospital based, retrospective cross sectional study involving 321 digital Orthopantomographs. Chi square test was employed to test significant differences.

Results: At 6-7.99 and 8-9.99 years, 20-21.4\% and 66\% of root apices of the mandibular central incisors had closed, respectively. At 8-11.99 years, 69\% of the maxillary right first molars in males had apices closed compared to $47 \%$ in females $(\mathrm{p}<0.05)$. At $8-11.99$ years, $84 \%$ of the mandibular central incisors had apices closed compared to $63 \%$ of maxillary ones $(\mathrm{p}<0.001)$.

Conclusion: Permanent incisor and first molar root apices' closure in Tanzanian sample seem to be early being in agreement with the permanent teeth emergence pattern reported earlier among Tanzanian children.
\end{abstract}

Keywords: Apex closure, permanent incisors, permanent first molars, Tanzania

\section{Introduction}

Tooth formation, eruption and emergence up to a functional position in the oral cavity involve a period of early development in a cellular state, followed by a period of formation of hard tissues of the crown. After the crowns of the permanent incisors and first molars are formed, there is an interval of latency until the commencement of eruption process of the tooth when it becomes active again and enters into a period of root formation. Tooth eruption is a process whereby the forming tooth migrates from its intraosseous location in the jaw to its functional position within the oral cavity. Root formation does not properly begin until the teeth start their movement towards the oral cavity.

A tooth or root apex is the tip or terminal end of the root of a tooth, the farthest part from the occlusal or incisal side [1]. A closed tooth root apex is whereby a mature permanent tooth having undergone calcification, gives the appearance of being closed, in spite of the presence of one or more foramina communicating with the outside of the tooth pulp. It has been reported that development of the root(s) of permanent tooth or teeth is complete to its apex closure in two to three years after the tooth emerges into the oral cavity $[2,3]$.

Apparently dentists treating children need to keep track of root development thus root apex closure. Development status of the root apex of permanent teeth is important in the treatment planning in orthodontics, paediatric dentistry and endodontics as well as in forensic dentistry [4]. The knowledge of root apex closure is used by orthodontists to determine the 
appropriate time to start orthodontic treatment. The duration of orthodontic treatment for teeth with closed root apices is shorter and results are more stable [5]. In paediatric dentistry root apex closure directs the choice of treatment particularly in dental traumatology where for instance a moderately intruded tooth with an open apex is advocated for passive repositioning, the tooth with a closed apex is repositioned surgically or orthodontically [6]. In addition, the information on root apex closure is useful for evaluation of growth and development of healthy children both in paediatric dentistry and general paediatrics. Paediatric dentists and paediatricians are also interested to know if dental and skeletal maturity of a child with certain disease is delayed or advanced [4]. In paediatric endocrinology and forensic dentistry the knowledge of root apex closure is used for estimation of age or identification of children by correlating between dental and chronological age $[4,7,8]$. In endodontic treatment, information on root apex closure helps the clinician to make decision, whereas for a closed root apex of a permanent tooth, root canal treatment is chosen, and for an open apex apexification or apexogenesis may be performed [9].

The development of teeth, occlusion and consequently root apices closure is to a large extent under genetic control [10-13] but it is also subject to environmental influence [13]. Within various populations, there is a difference in the rate of development between boys and girls. The greatest degree of sexual dimorphism occurs during the root formation stages while the difference during the crown formation stages is negligible [14]. Permanent mandibular incisors have been reported to be ahead of their maxillary counterparts while mandibular and maxillary first molars develop at comparable ages [15].

With respect to variation in root apex closure of permanent teeth between various population groups; genetic factors, sex, race, vitamin $D$ imbalance and other systemic disorders have been reported to be influencing factors. The root apices closure of permanent teeth has been reported to vary with sex, females being one year earlier than boys [16]. No significant difference of root apices closure of permanent incisors and first molars have been reported between right and left teeth of the same arches $[17,18]$.

Moreover, a Tanzanian study by Mugonzibwa et al. [19] reported that permanent teeth of the first transitional period were already emerging at the age of $3.5-5$ years. Such variance in the age of emergence of permanent teeth between African and Caucasian children whereby in the European populations first transitional period emergence starts at 6 years of age [20], may also be extrapolated to timing of root apices closure of the permanent teeth.

Since both the hereditary factors and the environmental factors differ between and within population groups, the results obtained with one group cannot be considered universal with regard to the phenotypic development. For this reason, it is important to investigate the root apices closure of the permanent teeth in a large number of groups of subjects to represent different populations. Therefore, this study was conducted to assess the root apices closure of permanent incisors and first molars among Tanzanian children aged 6-15 years. The aim was accomplished.

\section{Material and methods}

This was a hospital based descriptive retrospective crosssectional study which was conducted at Aga Khan Hospital in Dar es Salaam. Aga Khan is one of the largest private, multispecialty hospital offering general medical services, specialist clinics including oral health services and state of the art diagnostic services which was the only hospital with digital Orthopantomographs (OPGs) archives in Dar es Salaam during the Study period.

\section{Study Population}

A total of 1,812 OPGs that were taken from April 2012 to December 2013 were retrieved from the Hospital electronic archives. Only 410 OPGs were of children aged 6 to 15 years and therefore eligible to be included in the study. A total of 89 OPGs were excluded if they belonged to patients with; developmental anomalies, pathological disease of the maxillary and/or mandibular arches. OPGs were also excluded if there were severe distortions of teeth where the root structures of the teeth were not clearly visible or OPGs with congenital bilaterally missing teeth. No sampling was done, instead all 321 Orthopantomographs of black African children were enrolled into the study (Figure 1).

\section{Data Collection}

Demographic data including children's birth date, residence and race were recorded directly from the registry's data base. The chronological age for each subject was calculated by subtracting the date when the radiograph was exposed from the birth date. Months were converted to two decimal years. Only one investigator (TM) collected the data. The investigator was thoroughly trained by an experienced dental radiologist on how to recognise an open and closed root apex from electronic OPGs. Determination of the status of the root apices was done by visual means. Twenty different OPGs were used for this exercise until the researcher and radiologist were satisfied of the consistency among them with kappa $=0.98$. The intra-examiner consistency was determined by double examination of every $15^{\text {th }}$ OPG and expressed as Kappa statistics (kappa value 0.88).

Digital OPGs meeting the inclusion criteria were retrieved directly from hospital electronic data base and recorded on compact discs. K-pacs software was installed on the computer to facilitate access and viewing of OPGs. The status of root apices closure of all permanent incisors and first molars on the left and right sides of the maxillary and mandibular arches were examined and recorded on the record form. Only teeth that were above the alveolar margin on the OPG were 


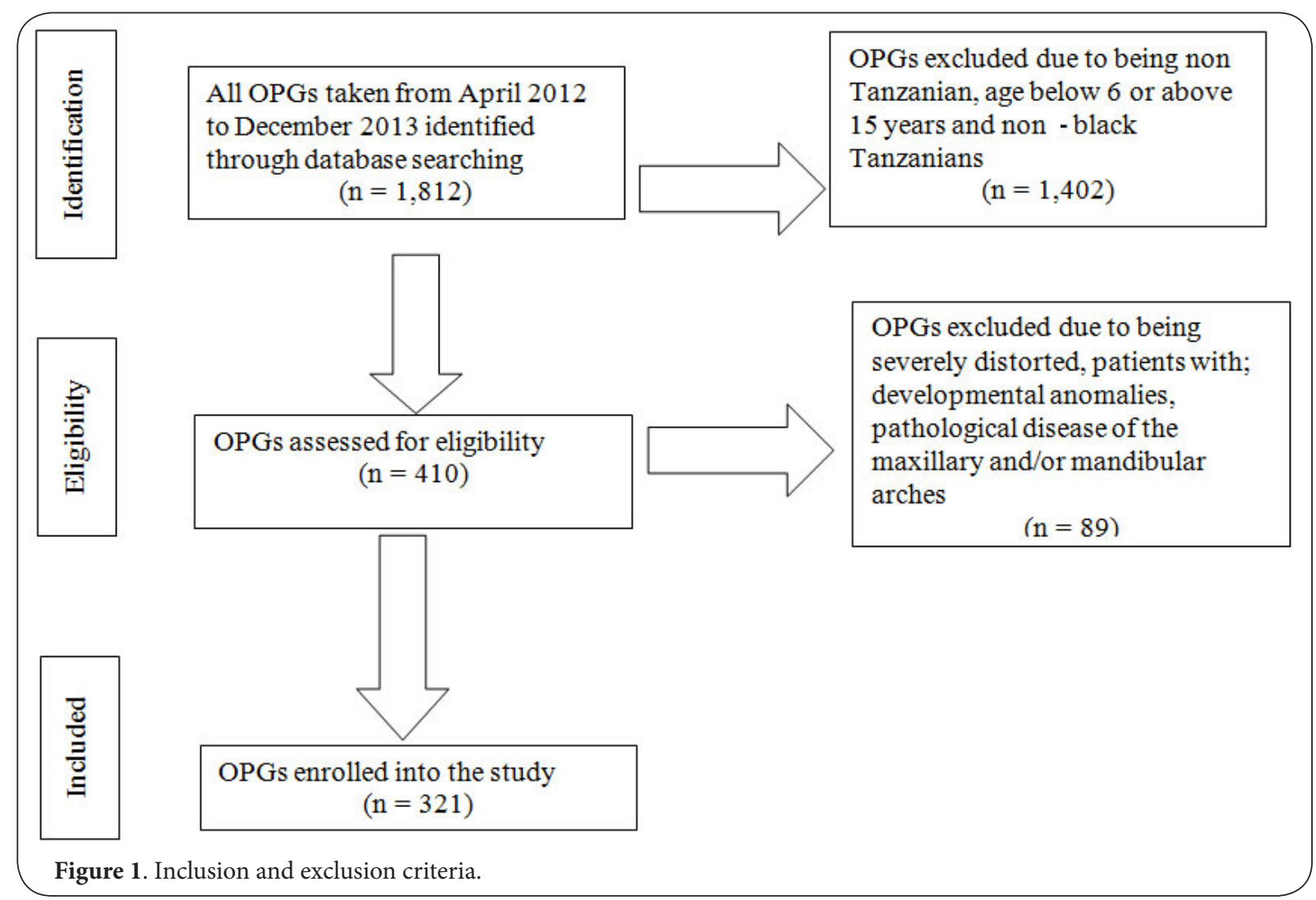

determined to have emerged into the oral cavity and their root development state were assessed. Root apices closure was defined and scored as follows: teeth with wide open root apices were scored as $0=$ Root apex still open and teeth with a tapered apex and gives the appearance of being closed were scored as $1=$ Root apex closed. Other scores defined and recorded included the following: Missing tooth $=7$; Not erupted $=8$; and not applicable for various reasons $=9$.

Data entry and analysis were done using SPSS 2002 version 16.0. Data were checked for clarity by running the frequency in order to remove the outliers and labelling missing values. The ages were grouped into five, 6-7.99 years, 8-9.99, 10-11.99 years, $12-13.99$ years and $14-15.60$ years. The tabulation of frequency distribution of root apices closure by age group of phase I dentition which are permanent incisors and first molars were done among the first three age groups (6-7.99 years, 8-9.99, 10-11.99 years) because above the age group of 10-11.99 years all teeth had root apices closed. Cross tabulations were done; chi square test was employed to test associations between root apex closure and age, sex, jaw and left or right side of the maxillary and mandibular arches.

Ethical clearance was granted by Muhimbili University of Health and allied sciences (MUHAS) ethical research committee. Permission to access the radiographs archives at Aga Khan Hospital was sought from appropriate hospital's administrative structures.

\section{Results}

The study sample consisted 321 OPGs of children aged between 6 to 15.60 years, of which; 176 (54.8\%) were of females. There were fewer OPGs 31 (9.6\%) in the older age group (14-15.60) compared to other age groups (Table 1).

Table 1. Distribution of study participants by age and sex.

\begin{tabular}{lllllll}
\hline $\begin{array}{l}\text { Age group } \\
\text { (years) }\end{array}$ & \multicolumn{3}{c}{ Male } & \multicolumn{3}{c}{ Female } \\
& N & $\%$ & N & $\%$ & N & $\%$ \\
\hline $6-7.99$ & 22 & 6.9 & 36 & 11.2 & 58 & 18.1 \\
$8-9.99$ & 27 & 8.4 & 41 & 12.8 & 68 & 21.2 \\
$10-11.99$ & 39 & 12.2 & 41 & 12.7 & 80 & 24.9 \\
$12-13.99$ & 44 & 13.7 & 40 & 12.5 & 84 & 26.2 \\
$14-15.60$ & 13 & 4.0 & 18 & 5.6 & 31 & 9.6 \\
Total & 145 & 45.2 & 176 & 54.8 & 321 & 100.0 \\
\hline
\end{tabular}

Mandibular central incisors had a considerable larger proportion of closed root apices 20-21.4\% at the age group 6-7.99 years and the only teeth whereby more than half $(66 \%)$ had root apices closed at the middle age group 8-9.99 years (Table 2). At the early age group (6-7.99 years) about $6 \%$ of maxillary incisors and first molars had closed root apices. In the older age group (10-11.99yrs), the proportions of mandibular teeth 
Mituro et al. Oral Biology and Dentistry 2018,

http://www.hoajonline.com/journals/pdf/2053-5775-6-1.pdf

doi: $10.7243 / 2053-5775-6-1$

Table 2. Proportion of closed root apices for permanent incisors and first molars by age group.

\begin{tabular}{|c|c|c|c|c|c|c|c|c|c|c|c|c|c|c|c|c|}
\hline \multirow[t]{2}{*}{$\begin{array}{l}\text { Age group } \\
\text { (years) }\end{array}$} & \multicolumn{2}{|c|}{$\begin{array}{l}16 \\
\text { Distal root }\end{array}$} & \multicolumn{2}{|c|}{$\begin{array}{l}16 \\
\text { Mesial root }\end{array}$} & \multicolumn{2}{|l|}{12} & \multicolumn{2}{|l|}{11} & \multicolumn{2}{|l|}{21} & \multicolumn{2}{|l|}{22} & \multicolumn{2}{|c|}{$\begin{array}{l}26 \\
\text { Mesial root }\end{array}$} & \multicolumn{2}{|c|}{$\begin{array}{l}26 \\
\text { Distal root }\end{array}$} \\
\hline & n & $\%$ & $\mathbf{n}$ & $\%$ & $\mathbf{n}$ & $\%$ & $\mathrm{n}$ & $\%$ & $\mathrm{n}$ & $\%$ & $\mathrm{n}$ & $\%$ & $\mathrm{n}$ & $\%$ & $\mathbf{n}$ & $\%$ \\
\hline \multicolumn{17}{|c|}{ Maxillary } \\
\hline $6-7.99$ & 2 & 4.3 & 3 & 6.2 & 2 & 7.4 & 3 & 5.3 & 3 & 5.7 & 2 & 6.5 & 3 & 6.2 & 4 & 8.7 \\
\hline $8-9.99$ & 16 & 29.6 & 17 & 29.8 & 16 & 28.9 & 19 & 30.2 & 20 & 31.7 & 19 & 35.2 & 28 & 44.4 & 24 & 42.1 \\
\hline $10-11.99$ & 45 & 83.3 & 49 & 83.1 & 51 & 81.0 & 63 & 87.5 & 64 & 90.1 & 60 & 84.5 & 63 & 91.3 & 59 & 92.2 \\
\hline \multicolumn{17}{|c|}{ Mandibular } \\
\hline $\begin{array}{l}\text { Age group } \\
\text { (years) }\end{array}$ & \multicolumn{2}{|c|}{$\begin{array}{l}46 \\
\text { Distal root }\end{array}$} & \multicolumn{2}{|c|}{$\begin{array}{l}46 \\
\text { Mesial root }\end{array}$} & \multicolumn{2}{|l|}{42} & \multicolumn{2}{|l|}{41} & \multicolumn{2}{|l|}{31} & \multicolumn{2}{|l|}{32} & \multicolumn{2}{|c|}{$\begin{array}{l}36 \\
\text { Mesial root }\end{array}$} & \multicolumn{2}{|c|}{$\begin{array}{l}36 \\
\text { Distal root }\end{array}$} \\
\hline 6-7.99 & 3 & 5.4 & 3 & 5.4 & 5 & 9.8 & 11 & 20.0 & 12 & 21.4 & 4 & 8.3 & 3 & 5.6 & 3 & 5.5 \\
\hline $8-9.99$ & 28 & 43.1 & 25 & 37.9 & 29 & 49.2 & 42 & 66.7 & 42 & 65.6 & 31 & 47.7 & 27 & 40.9 & 23 & 34.8 \\
\hline $10-11.99$ & 68 & 89.5 & 72 & 93.5 & 71 & 94.7 & 78 & 98.7 & 79 & 98.8 & 71 & 93.4 & 68 & 90.7 & 66 & 90.4 \\
\hline
\end{tabular}

${ }^{\star}$ FDI world dental federation notation: 46-mandibular right first molar, 42-mandibular right lateral incisor, 41-mandibular right central incisors, 31-mandibular left central incisor, 32-mandibular left lateral incisor, and 36-mandibular left first molar.

with closed apex were $98.8 \%$ for permanent central incisors; $93.4 \%$ to $94.7 \%$ lateral incisors and $89.5 \%$ to $93.5 \%$ first molars. In the older age group (10-11.99yrs) the proportions of maxillary permanent central incisors with closed apex were $87.5 \%$ to $90.1 \%$ and for first molars $83.1 \%$ to $92.2 \%$.

Only the upper right first molar showed significant differences of root apices closure by sex (Table 3), whereby $69.2 \%$ of the mesial root among males had apices closed compared

Table 3. Distribution of closed root apices of permanent incisors and first molars among 8-11.99 years children by sex.

\begin{tabular}{lllll}
\hline Tooth & \multicolumn{2}{l}{ Closed Root Apices } & Chi-Square & p-Value \\
& Male & Female & & \\
\hline 11 & $35(60.3 \%)$ & $47(61.0 \%)$ & 0.007 & 0.935 \\
12 & $28(59.9 \%)$ & $39(57.4 \%)$ & 0.071 & 0.790 \\
21 & $33(60.0 \%)$ & $51(64.6 \%)$ & 0.288 & 0.592 \\
22 & $33(62.3 \%)$ & $46(63.9 \%)$ & 0.035 & 0.852 \\
16 Mesial root & $36(69.2 \%)$ & $30(46.9 \%)$ & 5.847 & $\mathbf{0 . 0 1 6}$ \\
16 Distal root & $34(68.0 \%)$ & $27(46.6 \%)$ & 5.025 & $\mathbf{0 . 0 2 5}$ \\
26 Mesial root & $42(72.4 \%)$ & $49(66.2 \%)$ & 0.583 & 0.445 \\
26 Distal root & $39(73.6 \%)$ & $44(64.7 \%)$ & 1.090 & 0.296 \\
31 & $52(82.5 \%)$ & $65(85.2 \%)$ & 0.185 & 0.667 \\
32 & $43(71.7 \%)$ & $43(78.2 \%)$ & 0.024 & 0.878 \\
41 & $53(84.1 \%)$ & $67(84.8 \%)$ & 0.012 & 0.911 \\
42 & $45(76.3 \%)$ & $55(73.3 \%)$ & 0.151 & 0.698 \\
36 Mesial root & $34(68.0 \%)$ & $27(46.6 \%)$ & 0.475 & 0.491 \\
36 Distal root & $39(73.6 \%)$ & $44(64.7 \%)$ & 0.113 & 0.737 \\
46 Mesial root & $44(66.8 \%)$ & $53(66.2 \%)$ & 0.208 & 0.648 \\
46 Distal root & $44(71.0 \%)$ & $52(65.8 \%)$ & 0.423 & 0.515 \\
\hline
\end{tabular}

${ }^{\star}$ FDI world dental federation notation: 11-maxillary right central incisor, 12-maxillary right lateral incisor, 21-maxillary left central incisor, 22-maxilla left lateral incisor, 16-maxillary right first molar, 26-maxillary left first molar, 31-mandibular left central incisor, 32-mandibular left lateral incisor, 41-mandibular right central incisor, 42-mandibular right lateral incisor, 36-mandibular left first molar, 46-mandibular right first molar. to $46.9 \%$ among females $(p=0.01$ ) and $68 \%$ of the distal root among males compared to $46.6 \%$ of females ( $p=0.02$ ).

Significant differences were observed on closure of root apices between left and right sides of the maxillary roots of permanent first molars, the left side being ahead of the right (Table 4). About $69 \%$ of the roots for the left first molars had apices closed compared to nearly $57 \%$ of the roots on the right side, $(p<0.05)$.

Table 4. Comparison of closed root apices of permanent teeth between left and right sides of the maxillary and mandibular arches among 8-11.99 years children.

\begin{tabular}{lllllll}
\hline Maxillary arch & \multicolumn{2}{l}{$\begin{array}{l}\text { Central } \\
\text { incisors }\end{array}$} & \multicolumn{2}{l}{$\begin{array}{l}\text { Lateral } \\
\text { incisors }\end{array}$} & \multicolumn{2}{l}{ First molar } \\
\cline { 2 - 7 } & $\mathbf{n}$ & $\mathbf{\%}$ & $\mathbf{n}$ & $\mathbf{\%}$ & $\mathbf{n}$ & \% \\
\hline Left side & 84 & 62.7 & 79 & 63.2 & 91 & 68.9 \\
Right side & 82 & 60.7 & 67 & 56.3 & 66 & 56.9 \\
p-value & 0.742 & & 0.271 & & $\mathbf{0 . 0 4 9}$ & \\
\hline Mandibular Arch & Central & \multicolumn{2}{l}{ Lateral } & First molar \\
& incisors & incisors & & \\
\cline { 2 - 7 } & $\mathrm{n}$ & $\%$ & $\mathrm{n}$ & $\%$ & $\mathrm{n}$ & $\%$ \\
\hline Left side & 121 & 84.0 & 102 & 72.3 & 95 & 67.4 \\
Right side & 120 & 84.5 & 100 & 76.4 & 97 & 67.8 \\
p-value & 0.911 & & 0.668 & & 0.935 & \\
\hline
\end{tabular}

Significant differences in closed root apices by arches were observed for central incisors (Table 5). Eighty four percent of the mandibular central incisors had their root apices closed compared to about three fifth (63\%) of the maxillary central incisors at age 8-11.99 $(p<0.001)$.

\section{Discussion}

Interpretation of the findings should bear in mind that the study was hospital based, therefore; it may not reflect the 
Mituro et al. Oral Biology and Dentistry 2018,

http://www.hoajonline.com/journals/pdf/2053-5775-6-1.pdf

Table 5. Comparison of root apices closure of permanent teeth between maxillary and mandibular arches among 8-11.99 years children.

\begin{tabular}{lllllll}
\hline Arch Bone & \multicolumn{2}{c}{ Central Incisors } & \multicolumn{2}{c}{ Lateral Incisors } & \multicolumn{2}{l}{ First Molar } \\
\cline { 2 - 7 } & $\mathrm{n}$ & $\%$ & $\mathrm{n}$ & $\%$ & $\mathrm{n}$ & $\%$ \\
\hline Maxillary & 84 & 62.7 & 79 & 63.2 & 91 & 68.9 \\
Mandibular & 121 & 84.0 & 102 & 72.3 & 95 & 67.4 \\
p-Value & $\mathbf{0 . 0 0 0}$ & & 0.111 & & 0.782 & \\
\hline
\end{tabular}

community situation. In addition, it was a cross sectional study, thus it may not give exact age of the tooth root apex closure. Information regarding race relied on what was retrieved from the records (paternal race) consequently the mixed races (parents from different races) could not be identified. Furthermore, the study involved OPGs which could not provide additional information for the subjects such as history of trauma. Since, trauma delays apex closure, this may have contributed to study limitations.

The observed adequate number of OPGs for the younger age group (6-7.99 years) is probably because among Tanzanian children phase 2 of permanent teeth start to emerge into the oral cavity at these ages as was reported by Mugonzibwa et al. [19], while crowding also start to be seen at young ages which necessitates seeking orthodontic consultation. Our findings are contrally to the study by AL Emran [21] in Saudi Arabia, who reported to exclude children aged below 8.5 years from the study because there were fewer numbers of OPGs because panoramic radiographs were rarely taken as dental investigation for that age group.

Mandibular central incisors had a considerable proportion (21.4\%) of closed root apices at the age group 6-7.99 years, whereas at age group 10-11.99 years, $90 \%$ of the root apices for first molars and $98 \%$ for mandibular central incisors were closed. Based on the report by Ngassapa et al. [3] root apices closure occurs 2 to 3 years after tooth emergence. Therefore, the findings of permanent first molars' and mandibular central incisors' root apices closure are in line with their age of emergence into the oral cavity as reported by Mugonzibwa et al. [19]. Our findings are contrary to those of Demirjian and Levesque [22] who reported root apices to close four years after tooth emergence among Canadian children. Relatively early apex closure suggests an alert to clinicians when making treatment decision for orthodontics, trauma or endodontics in children especially in countries where availability of diagnostic services like x-ray is not always guaranteed.

Contrary to a number of several reports accessed from the literature that observed females maturing earlier than males $[16,23]$, there were no sex differences of root apices closure of the permanent incisors and first molars in both arches, except for the permanent maxillary right first molars which could have been by chance. The present findings also form the baseline data for the Tanzanian population as there was no reference data for comparison. The observed diferences between Tanzanian findings with other studies may be due to chance, diferences in study design, criteia, data presentation as well as different types and/or quality of analysis.

The observed significant differences of root apices closure between left and right side of maxillary first molars could have been due to chance, though earlier Nolla [17] reported few development differences between right and left teeth of the same type. Other maxillary and mandibular teeth had no differences in apices closure between the two sides. This similarity between the left and right sides of the maxillary and mandibular arches agrees with the findings by El Hafez [24]. Root apices closure of mandibular central incisors was significantly ahead of maxillary ones, largely because emergence of mandibular central incisors precedes the maxillary central incisors. Similar findings were reported in Egypt by El Hafez [24].

\section{Conclusion and recommendation}

Most root apices closure of permanent incisors and first molars among children in the studied sample are early compared to earlier reports being in agreement with the permanent teeth emergence pattern that has been reported earlier in the Tanzanian children samples. Seldom, the root apex closure varied with sex and jaws as well as right and left sides. We recommend more studies involving large samples to be conducted in Tanzania in order to obtain representative information for the whole country and to compare tooth emergence as well as root apex closures of permanent teeth in Tanzanian children population.

\section{List of abreviations}

MUHAS: Muhimbili University of Health and Allied Sciences

OPG: Orthopantomograph

SPSS: Statistical Package for Social Sciences

\section{Competing interests}

The authors declare that they have no competing interests.

Authors' contributions

\begin{tabular}{|l|l|l|l|}
\hline Authors' contributions & THM & EAM & FKK \\
\hline Research concept and design & $\checkmark$ & $\checkmark$ & $\checkmark$ \\
\hline Collection and/or assembly of data & $\checkmark$ & -- & -- \\
\hline Data analysis and interpretation & $\checkmark$ & $\checkmark$ & $\checkmark$ \\
\hline Writing the article & -- & $\checkmark$ & -- \\
\hline Critical revision of the article & $\checkmark$ & -- & $\checkmark$ \\
\hline Final approval of article & $\checkmark$ & $\checkmark$ & $\checkmark$ \\
\hline Statistical analysis & $\checkmark$ & -- & -- \\
\hline
\end{tabular}

\section{Acknowledgement}

The authors are grateful to the Aga Khan Hospital authorities for allowing them to access the hospital clinical data bank of the digital OPGs. Thanks to the Tanzanian Government through the Ministry of Health, Community Development, Gender, Elderly and Children for funding the study.

\section{Publication history}

EIC: Thimios A. Mitsiadis, University of Zurich, Switzerland. Received: 11-Jan-2018 Final Revised: 15-Feb-2018 Accepted: 16-Mar-2018 Published: 25-Mar-2018 
Mituro et al. Oral Biology and Dentistry 2018,

\section{References}

1. Jablonski S. Illustrated dictionary of dentistry. Philadelphia, W.B. Saunders Company. 1982.

2. Scott JH and Simon NBB. The establishment of deciduous and permanent dentitions. In Scott JH and Simon NBB "Introduction to Dental anatomy". Churchil livingstone, Edinburgh London and Newyork. 1977; 120-121.

3. Ngassapa D, Hassanali J, Amwayi P and Guthua S. Essentials of Oralfacial anatomy. Overview on tooth development, calcification and eruption. Dar es salaam University press. 1996.

4. Ogodescu AE, Ogodescu A, Szabo K, Tudor A and Bratu E. Dental Maturity a biologic indicator of chronological age: Digital radiographic study to assess Dental age in Romanian children. Int J Biol Biom Eng. 2011; 1:32-40. | Pdf

5. Sukhia RH, Fida M and Azam SI. Dental age table for a sample of Pakistani children. Eur J Orthod. 2012; 34:77-82. | Article | PubMed

6. Albadri S, Zaitoun $\mathrm{H}$ and Kinirons M. UK National Clinical Guidelines in Paediatric Dentistry. Treatment of traumatically intruded permanent incisor teeth in children. Int J. 2010. | Article

7. Butti AC, Clivio A, Ferraroni M, Spada E, Testa A and Salvato A. Haavikko's method to assess dental age in Italian children. Eur J Orthod. 2009; 31:150-5. | Article | PubMed

8. Foti B, Lalys L, Adalian P, Giustiniani J, Maczel M, Signoli M, Dutour O and Leonetti $G$. New forensic approach to age determination in children based on tooth eruption. Forensic Sci Int. 2003; 132:49-56. | Article | PubMed

9. Rafter M. Apexification: a review. Dent Traumatol. 2005; 21:1-8. | Article I PubMed

10. Lewis $A B$ and Garn $S M$. The relationship between tooth formation and other maturational factors. Angle Orthod. 1960; 30:70-77.

11. Garn SM, Lewis AB and Kerewsky RS. Genetic, Nutritional, and Maturational Correlates of Dental Development. J Dent Res. 1965; 44:SUPPL:228-42. | PubMed

12. Pelsmaekers $B$, Loos $R$, Carels $C$, Derom $C$ and Vlietinck $R$. The genetic contribution to dental maturation. J Dent Res. 1997; 76:1337-40. | Article | PubMed

13. Townsend G, Hughes T, Luciano M, Bockmann M and Brook A. Genetic and environmental influences on human dental variation: a critical evaluation of studies involving twins. Arch Oral Biol. 2009; 54 Suppl 1:S45-51. | Article | PubMed Abstract | PubMed FullText

14. Merwin DR and Harris EF. Sibling similarities in the tempo of human tooth mineralization. Arch Oral Biol. 1998; 43:205-10. | Article | PubMed

15. American Academy of Pediatric Dentistry. Dental Growth and Development. 2017. | Pdf

16. Teivens $A$ and Mornstad $H$. A comparison between dental maturity rate in the Swedish and Korean populations using a modified Demirjian method. J Forensic Odontostomatol. 2001; 19:31-5. | PubMed

17. Nolla CM. The development of the permanent teeth. J Dent Child. 1960; 27:254-266.

18. Demirjian A, Goldstein $\mathrm{H}$ and Tanner JM. A new system of dental age assessment. Hum Biol. 1973; 45:211-27. | PubMed

19. Mugonzibwa EA, Kuijpers-Jagtman AM, Laine-Alava MT and van't Hof MA. Emergence of permanent teeth in Tanzanian children. Community Dent Oral Epidemiol. 2002; 30:455-62. | Article | PubMed

20. Eskeli R, Laine-Alava MT, Hausen $\mathrm{H}$ and Pahkala R. Standards for permanent tooth emergence in Finnish children. Angle Orthod. 1999; 69:529-33. | Article | PubMed

21. Al-Emran S. Dental age assessment of 8.5 to 17 Year-old Saudi children using Demirjian's method. J Contemp Dent Pract. 2008; 9:64-71. PubMed

22. Demirjian $A$ and Levesque GY. Sexual differences in dental development and prediction of emergence. J Dent Res. 1980; 59:1110-22. | Article | PubMed
23. Uys A. A pilot study to assess dental age estimation in black South African children using Demirjian's method. 2012.

24. El Hafez M. A. Dental maturation assessment by Nolla's technique on a group of Egyptian children. Aust J Basic App/ Sci. 2008; 2:1418-1424. I $\underline{\text { Pdf }}$

\section{Citation:}

Mituro TH, Mugonzibwa EA and Kahabuka FK. A retrospective study of root apices closure of permanent incisors and first molars in Tanzanian children's digital Orthopantomographs. Oral Biol Dent. 2018; 6:1.

http://dx.doi.org/10.7243/2053-5775-6-1 